\title{
Repositorio Nacional Digital de Acceso Libre (ALICIA): oportunidad para el acceso a la información científica en el Perú
}

National digital open access repository (ALICIA): an opportunity for access to scientific information in Peru

\author{
Noé Atamari-Anahui ${ }^{1,2, a}$, Cristian Díaz-Vélez ${ }^{3, b}$ \\ ${ }^{1}$ Asociación Científica de Estudiantes de Medicina Humana (ASOCIEMH-CUSCO), Cusco, Perú. \\ ${ }^{2}$ Facultad de Medicina Humana, Universidad Nacional San Antonio Abad del Cusco, Perú. \\ ${ }^{3}$ Dirección de investigación, Hospital Regional de Lambayeque, Chiclayo, Perú. \\ ${ }^{a}$ Estudiante de Medicina; ${ }^{b}$ Médico epidemiólogo.
}

An Fac med. 2015;76(1):81/ doi:10.15381/anales.v76i1.11081

Señor Editor:

El desarrollo de la informática en el Perú surge como una tendencia global ante la necesidad de generar soluciones a diversos problemas utilizando las tecnologías de información y comunicación en diferentes ejes temáticos, dentro de los cuales destacan las ciencias de la salud.

Un aspecto importante de este proceso de cambio a través del uso de la tecnología es el acceso a la información científica. Recientemente, el Consejo Nacional de Ciencia, Tecnología e Innovación Tecnológica (CONCYTEC) ha implementado el Repositorio $\mathrm{Na}$ cional Digital de acceso libre denominado ALICIA (Acceso Libre a la Información para la Innovación), con el objetivo de difundir y promover el intercambio de información entre las instituciones y universidades del Perú en distintas áreas ${ }^{(1)}$.

Con esto, CONCYTEC busca promover la investigación y la información científica mediante la integración de repositorios nacionales que contienen libros, tesis, artículos de revistas, además de datos y análisis estadísticos para la generación de nuevo conocimiento. Se promueve un cambio de cultura en el uso de la información en beneficio de la sociedad, puesto que existe una gran cantidad de literatura gris por la poca costumbre de publicar y ello posiblemente porque aún no se considera la publicación como parte importante del proceso de investigación. La aplica- ción de ALICIA es de carácter obligatorio para todas aquellas instituciones que reciben financiamiento del Estado, pues nace en base a la Ley $N^{\circ} 30035$ promulgada en junio de 2013, dándonos a conocer el acceso libre a la información digital, resultado de la producción en ciencia, tecnología e innovación del país ${ }^{(2)}$.

Diversos países en Sudamérica ya vienen trabajando estrategias similares; tal es el caso de Argentina, que implementó el Sistema Nacional de Repositorios Digitales (SNRD) para promover el acceso abierto e intercambio de la producción científica y tecnológica generada en ese país, haciéndola más visible en la comunidad científica y la ciudadanía en general ${ }^{(3)}$.

El desarrollo y la aplicación de nuevas herramientas para el intercambio de información es importante y más aún en ciencias de la salud ${ }^{(4)}$, especialmente cuando esta nos permite el acceso libre de información a toda la población en general (ciudadanos, estudiantes y profesionales), como propone ALICIA. Es necesario estar informados de los avances que nos trae la ciencia y la correcta aplicación de esta, así como de la producción científica en diversas áreas, dentro de ellas las ciencias de la salud. Por ello, es importante promover e incentivar la investigación desde las universidades, más aún en pregrado, donde los estudiantes están en plena formación y prestos para aprender el proceso adecuado de investigación (diseño, ejecución, análisis y publicación de resultados); además de superar el limitado acceso a las principales bases de datos a los estudiantes investigadores, que les permita obtener un amplio panorama en sus investigaciones y culminarlas estas con la mejor calidad posible.

\section{REFERENCIAS BIBLIOGRÁFICAS}

1. CONCYTEC. Acceso Libre a Información Científica para la Innovación. (ALICIA). [Internet]. [Citado 08 de octubre de 2014]. Disponible en: http://alicia. concytec.gob.pe/alicia/

2. Congreso de la República del Perú. Ley que regula el repositorio nacional digital de ciencia, tecnologia e innovación de acceso abierto. [Internet]. [Citado 26 de setiembre de 2014]. Disponible en: http://portal.concytec.gob.pe/images/stories/images2013/ portal/areas-institucion/dsic/ley-30035.pdf

3. Bongiovani P, Nakano S. Acceso Abierto en Argentina: la experiencia de articulación y coordinación institucional de los repositorios digitales en ciencia y tecnología. E-Colab. 2011;1(2):163-79.

4. Galán-Rodas E, Egoavil MS. Herramientas de productividad para el profesional médico y la investigación. Acta Méd Peru. 2013;30(3):143-7.

Agradecimientos: Al Dr. Edén Galán Rodas, por las observaciones y sugerencias que hiciera al manuscrito. Fuentes de financiamiento: Autofinanciado.

Carta recibida el 6 de enero de 2015.

Conflictos de interés: Los autores declaran no tener conflictos de interés.

Correspondencia:

Noé Atamari Anahui

Dirección: Calle Los Geranios B-2 San Sebastián, Cusco, Perú

Teléfono: 950383376

Correo electrónico: noe.atamari@gmail.com 